Makalenin Türü / Article Type Geliş Tarihi / Date Received Kabul Tarihi / Date Accepted Yayın Tarihi / Date Published
: Araștırma Makalesi / Researh Article

: 23.11.2018

: 26.09.2019

: 11.10 .2019

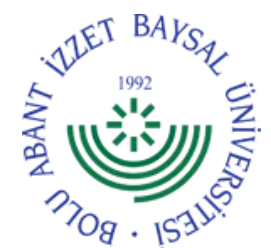

\title{
GÖRSEL MATEMATİK OKUR YAZARLIĞI ÖZ-YETERLİK ALGISI İLE ÜSTBİLIŞSEL OKUDUĞUNU ANLAMA FARKINDALIĞI ARASINDAKİ İLIŞKİ*
}

\author{
Zeki AKSU'1 , Selcen ÇALIK UZUN², Sedef ÇELIK ${ }^{3}$
}

\section{ÖZ}

$\mathrm{Bu}$ araştırmanın amacı ortaokul öğrencilerinin görsel matematik okuryazarlık öz-yeterlik algıları (GMOÖA) ile üstbilişsel okuduğunu anlama farkındalığı (ÜOAF) arasındaki ilişkileri incelemektir. Araştırma, Doğu Karadeniz Bölgesi’nin bir ilindeki ortaokullarda 7. Sınıfta öğrenim gören toplam 301 öğrenci ile yürütülmüştür. Araştırmada veri toplama araçları olarak Duran (2011) tarafindan geliştirilen Görsel Matematik Okuryazarlığı Öz-yeterlik Algısı Ölçeği (GMOÖAÖ) ile Gelen (2003) tarafından geliştirilip Çakıroğlu (2007) tarafından uyarlanan Üstbilişsel Okuduğunu Anlama Farkındalığı Ölçeği (ÜOAFÖ) kullanılmıştır. Araştırma nicel araştırma yöntemlerinden ilişkisel modele uygun olarak gerçekleştirilmiştir. Analiz için SPSS 19.0 programından faydalanılmıştır. İlgilenilen değişkenler açısından cinsiyete göre bir farklılık olup olmadığını tespit edebilmek için analiz yöntemi olarak bağımsız örneklem $t$ testi kullanılmıştır. Verilerin analizinde basit korelasyon analizi ve basit doğrusal regresyon analizi kullanılmıştır. Bu araştırma için görsel matematik okuryazarlık öz-yeterlik algıları ve üstbilişsel okuduğunu anlama farkındalığı ölçeğinin Cronbach Alfa güvenirlik katsayıları sırasıyla 94 ve .77 bulunmuştur. Çalışmanın sonucunda yukarıda bahsedilen yapılar arasında pozitif yönde orta düzeyde bir ilişki $(r=.51)$ olduğu ortaya çıkmıştır. Çalışmada öğrencilerin görsel matematik okuryazarlığı öz-yeterlik algılarının, üstbilişsel okuduğunu anlama farkındalık düzeylerini pozitif yönde anlamlı bir şekilde yordadığı sonucuna ulaşılmıştır.

Anahtar Kelimeler: Görsel matematik okuryazarlığı, üstbilişsel okuma, öz-yeterlik.

\section{THE RELATIONSHIP BETWEEN VISUAL MATHEMATICS LITERACY SELF- EFFICACY PERCEPTIONS AND METACOGNITIVE READING COMPREHENSION AWARENESS}

\begin{abstract}
The purpose of the research is to investigate the relationships between visual mathematics literacy self-efficacy perceptions (VMLSP) and metacognitive reading comprehension awareness (MRCA). The research was conducted with 301 students who are enrolled in middle schools (7th grade) where a city is located in the Eastern Black Sea Region. The present study was done with a total of 301 students. The VMLSP scale, developed by Duran (2011) was used as a data collection tool in this study. And MRCA scale, which was developed by Gelen (2003) and Çakıroğlu (2007) extracted some items from this scale and then performed its validity and reliability. The research was conducted according to the relational model as a quantitative research method. SPSS 19.0 program was used to analyze the data. Simple correlation analysis and simple linear regression analysis were used in the analysis of the data. For this study, Cronbach's alpha reliability coefficients of visual mathematics literacy self-efficacy perceptions (VMLSP) and metacognitive reading comprehension awareness scales were .94 and .77respectively. As a result of the study, it was found that there is a moderate correlation $(r=.51)$ in the positive direction between the above mentioned structures. Independent sample t test was used as an analysis method in order to determine whether there is a difference according to the sex in terms of the variables of interest. Discussions of research findings in the current study were given in more detail.
\end{abstract}

Keywords: Visual mathematics literacy, metacognitive reading, self-efficacy.

\footnotetext{
"Bu makalenin bir kismı International Conference on Education in Mathematics, Science Technology (ICEMST), konferansinda sunulmuştur. Mayls, 2017.

${ }^{1}$ Artvin Çoruh Üniversitesi, Eğitim Fakültesi, zekiaksu25@artvin.edu.tr, ㄴ https://orcid.org/0000-0001-6839-6847

${ }^{2}$ Artvin Çoruh Üniversitesi, Eğitim Fakültesi, sclkuzun@artvin.edu.tr, (1) https://orcid.org/0000-0002-2178-6642

${ }^{3}$ Artvin Çoruh Üniversitesi, Eğitim Fakültesi, sedefcelik@artvin.edu.tr, 느ttps://orcid.org/0000-0002-9242-8009
} 


\section{GíRIŞ}

Uluslararası Öğrenci Başarılarını Değerlendirme Programı (The Programme for International Student Assessment [PISA]), Ekonomik Kalkınma ve İşbirliği Örgütü (Organisation for Economic Co-operation and Development [OECD]) tarafından 1997'de geliştirilmiş olup uluslararası boyutta üç yılda bir 15 yaşındaki öğrencilerin başarısını sınamaktadır. PISA'da temel olarak örgün eğitime devam eden 15 yaş grubundaki öğrencilerin; Matematik okuryazarlığı, Fen Bilimleri okuryazarlığı ve Okuma Becerileri konu alanları ile ilgili veriler toplanmaktadır. PISA, OECD'nin bir eğitim araştırmasıdır. Bu araştırma, OECD Eğitim Direktörlüğü’ne bağlı olan PISA Yönetim Kurulu tarafından yürütülmektedir. OECD ülkeleri eğitim alanında yapılan ulusal değerlendirme çalışmalarının yanı sıra, uluslararası düzeyde konumlarını belirlemek amacıyla eğitim göstergelerine ihtiyaç duymaktadırlar. Türkiye'de OECD üyesi olarak, eğitim düzeyinin yükseltilmesi amacıyla bu araştırmaya katılmaktadır. OECD ülkelerinin PISA ışığında matematik ve matematik eğitimine bu kadar önem vermesinin altında birçok ekonomik sebep yatmaktadır. Çünkü öğrencilerin sahip olacağı matematik becerileri ile onların ilerdeki iş hayatlarındaki başarıları arasında doğrudan ilişki bulunacağı düşünülmektedir.

PISA 2012'de matematik okuryazarlı̆̆ı, çeşitli bağlamlarda bireyin formüle etme, matematiği kullanma ve yorumlama kapasitesi olarak tanımlanmaktadır. Bu kapasite matematiksel olarak akıl yürütmeyi; bir olguyu açıklamak ve tahmin edebilmek için matematiksel kavramları, işlemleri ve araçları kullanmayı içerir. Matematik okuryazarlığı bireyin; dünyada matematiğin oynadığı rolü fark etmesine ve anlamasına, sağlam temellere dayanan yargılara ulaşmasına ve yapıcı, ilgili, duyarlı bir vatandaş olarak kendi ihtiyaçlarını karşılayabilecek şekilde matematiği kullanmasına yardımcı olmaktadır (MEB, 2011). Özgen ve Bindak (2011), matematik okuryazarlığının çıkış nedeni olarak bireylerin günlük hayatlarında, iş-okul yaşamlarında karşılaştıkları matematiksel içerik, süreç ve durumlarda yetkin olabilmelerinin gerekliliğini ve önemini vurgulamışlardır.

PISA'daki matematik okuryazarlı̆̆ dışında farklı dersler için de tanımlanan okuryazarlık türleri vardır. Ayrıca bunlar dışında son yıllarda öğrenim-öğretim sürecinde karşımıza çıkan ve önemli görülen bir diğer okuryazarlık türü de görsel okuryazarlıktır. Çünkü görsel okuryazarlık becerisine sahip bir öğrencinin, derslerde kendisine sunulan görsellerin altında yatan mesajları daha iyi anlayabileceği düşünülmektedir (Şahin, Kurudayığlu \& Çelik, 2013). Bu nedenle görselleri anlamak ve anlatmak için tamamen görselliğe yönelik bir okuryazarlık türüne ihtiyaç, duyulmuştur (Göçer \& Tabak, 2013). Matematikte görsel olan şekilleri, tabloları, grafikleri, resimleri, görsel olmayan şekilleri vd. okuyabilme, yorumlayabilme, değerlendirebilme, kullanabilme ve yeni görsel durumlar oluşturabilme becerisi için yeni bir kavram olan görsel matematik okuryazarlığı ortaya çıkmıştır (Çilingir \& Artut, 2016). Bekdemir ve Duran (2012), Görsel Matematik Okuryazarlı̆̆ını (GMOY) günlük yaşamda ortaya çıkan deneyimlenebilecek problemleri görsel veya uzamsal, tersine görsel veya uzamsal bilgileri de matematiksel olarak algılayabilme, ifade edebilme, yorumlayabilme, değerlendirme, uygulama ve kullanabilme yeterliği şeklinde tanımlamışlardır.

PISA'da okuma becerileri ile "okuma becerileri okuryazarlı̆̆ı" kastedilmektedir. "Okuryazarlık" terimi bilgiyi anlamaya ve iletmeye yarayan araç anlamında kullanılmıştır. PISA'da "okuma becerileri okuryazarlığı" terimi okumanın etkin bir şekilde belirli bir amaca ve göreve yönelik gerçekleştirilmesini ifade etmektedir (MEB, 2015). Okuma becerilerinde ele alınan bilişsel yeterlikler; bir metni basit olarak çözümlemekten ziyade sözcük bilgisini, dilbilgisini, dilbilimsel ve metinsel yapı ve özellikleri bilmeyi, yaşadığımız dünya hakkında bilgi sahibi olmayı gerektirmektedir. Bununla birlikte PISA, okuma becerilerinde metni çözümlerken uygun stratejileri kullanma becerisi ve bu becerilerin farkındalığı gibi üst düzey bilişsel becerileri de değerlendirmektedir (MEB, 2011).

Gelen (2003), iyi okuyucuların yani bilişsel ve üst-bilişsel becerilere sahip olanların okumaya dikkatlerini verdiklerini, metni okuma öncesinde tahmin edebildiklerini, okuma stratejileri kullandıkların, içeriği analiz edebildiklerini, anahtar kelimeleri belirleyebildiklerini ifade etmiştir. Kuruyer ve Özsoy (2016), iyi okuyucuların, bilişsel süreçlerinin farkında olduklarını ve bu süreçleri okuma ortamında etkili bir şekilde kullandıklarını ve üst bilişsel okuma becerileri gösterdiklerini belirtmiştir. Buradaki üstbiliş kavramı, kişinin kendi bilişsel süreçlerini ve düşüncelerini düzenleme, değerlendirme ve izleme bilgisi ve farkındalığı olarak tanımlanabilir (Bonds, Bonds \& Peach, 1992). Okuma ile ilgili üstbilişsel farkındalık öğrencilerin okuma süreçlerini izlemelerini ve kontrol etmelerini kolaylaştırarak öğrencilere okuma süreçlerini düzenleme şansı tanımaktadır (Bozkurt \& Memiş, 2013).

Yapılan çalışmalarda (Abu-Hilal, 2000; Chen, 2003; Blake ve Lesser, 2006; Ayotola ve Adedeji, 2009; Liu ve Koirala, 2009; Özgen ve Bindak, 2011; Şengül, Katrancı ve Gülbağc1, 2012) öğrencilerin matematik okuryazarlı̆̆ı ile matematik başarıları arasında anlamlı bir ilişki bulunmuştur. Bu ilişkiler araştırılırken bazı çalışmalarda (Çilingir, 2015; Şengül, Katrancı \& Gülbağc1, 2012; Tutkun, Erdoğan \& Öztürk, 2014) cinsiyet değiş̧keninin de dikkate alındığı görülmüştür. Ayrıca matematik eğitimcileri görsel/resimsel (visual/pictural) düşüncenin gücünü geliştirecek görsel matematikle ilgili çalışmaların ve etkinliklerin kullanılmasının gerekliliğini belirtmiştir (Bekdemir \& Duran, 2012; Göçer \& Tabak, 2013; Şahin, Kurudayığlu \& Çelik, 2013). Bununla birlikte, Tanoğlu, Taşkesen, Bakırhan ve Taşkesen (2017) yaptıkları çalışmada daha çok geometri ile görsel matematik okuryazarlığı öz-yeterlik algı puanları arasındaki ilişkiyi incelemiştir. Geometri dışındaki bir konunun öğrencilerin görsel 
matematik okuryazarlığı öz-yeterlik algı puanları üzerindeki etkisinin nasıl olacağı konusunun araştırılmaya değer olacağı düşünülmektedir.

Alanyazın incelendiğinde, öğrencilerin üstbilișsel okuduğunu anlama farkındalığı ile okuma motivasyonları ile okuma düzeyleri arasındaki ilişkilerin incelendiği tespit edilmiştir. Ayrıca bu konu alanındaki çalışmalarda (Bağçeci, Döş \& Sarıca, 2011; Bozkurt \& Memiş, 2013; Güngör, 2005) cinsiyet değişkenine yönelik de analizler yapıldığı görülmüştür. Yapılan bazı araştırmalarda kız öğrencilerin erkek öğrencilere göre üstbilişsel farkındalık puanlarının daha yüksek olduğu (Altındağ, 2008; Bağçeci vd., 2011; Karatay, 2010; Yavuz, 2009), bazı araştırmalar da ise cinsiyet açısından fark bulunmadığı (Duran, 2011; Özsoy vd, 2010) tespit edilmiş̧ir. Benzer çalışmalarda (Baydık, 2011; Bozkurt \& Memiş, 2013) öğrencilerin Türkçe, Matematik, Fen ve Sosyal Bilgiler derslerindeki akademik başarıları ile üstbilişsel okuduğunu anlama farkındalığı arasındaki ilişsilere de bakılması önerilmiştir. Tüm bu önerilerden yola çıkarak bu çalışmada, öğrencilerinin görsel matematik okuryazarlık algıları ile üstbilişsel okuduğunu anlama farkındalığı arasındaki ilişkilerin incelenmesi kararlaştırılmışıtır.

\subsection{Araştırmanın Amacı}

$\mathrm{Bu}$ araştırmanın amacı, ortaokul öğrencilerinin görsel matematik okuryazarlık algıları ile üstbilişsel okuduğunu anlama farkındalı̆̆ arasındaki ilişkileri incelemektir. Bu amaç doğrultusunda araştırmanın alt problemleri ise aşağıdaki gibi oluşturulmuştur:

1- Üstbilişsel okuduğunu anlama farkındalığı puanları kontrol edildiğinde öğrencilerin üstbilişsel okuduğunu anlama farkındalığı puanları cinsiyete göre anlamlı olarak farklılaşmakta mıdır?

2- Görsel matematik okuryazarlığı öz-yeterlik alg1 puanları kontrol edildiğinde öğrencilerin görsel matematik başarı puanları cinsiyete göre anlamlı olarak farklılaşmakta mıdır?

3- Öğrencilerin görsel matematik okuryazarlığı öz-yeterlik algıları ile üstbilişsel okuduğunu anlama farkındalığı arasında anlamlı bir ilişki var mıdır?

4- Öğrencilerin görsel matematik okuryazarlığı öz-yeterlik algıları, üstbilişsel okuduğunu anlama farkındalığı düzeylerinin anlamlı bir yordayıcısı mıdır?

\section{YÖNTEM}

Araştırmanın amacı ve alt amaçları doğrultusunda ilişkisel tarama modeli yapılmıştır. Karasar (2012) ilişkisel tarama modelini, iki ya da daha çok sayıdaki değiş̧en arasında birlikte değişim varlığını ve/veya derecesini belirlemeyi amaçlayan araştırma modeli olarak ifade etmektedir. Bu bağlamda üstbilişsel okuduğunu anlama farkındalı̆̆ı ile görsel matematik okuryazarlığı değişkenleri arasındaki ilişkilerin ortaya konması amaçlanmıştır.

\subsection{Katılımcilar}

Araştırma Doğu Karadeniz Bölgesi’nin bir ilinde ortaokullarda öğrenim gören öğrencilerle yapılmıştır. Araştırmanın amacına uygun olarak araştırmanın evreninin ortaokuldaki yedinci sınıf öğrencileri olarak belirlenmiştir. Görsel matematik okuryazarlığı ölçmek için kullanılacak veri toplama aracındaki bazı maddelerin yedinci sınıfta öğrenilen konular olduğu tespit edilmiştir. Örneğin ölçeğin 26. maddesindeki "çizgi grafiğinde verilen bilgilere göre istenen bir noktanın yerini gösterebilirim" ifadesini öğrencinin cevaplayabilmesi çizgi grafiğini görmüş olması gerekmektedir. Ortaokul matematik öğretim programında yer alan "verilere iliş̧kin çizgi grafiği oluşturur ve yorumlar" kazanımına göre çizgi grafiği yedinci sınıfta görülmektedir (MEB, 2017). Bu ve benzeri ölçek maddelerine ilişkin bazı soruların cevaplanabilmesi için yedinci sınıf öğrencileri tercih edilmiştir. Benzer şekilde diğer üst bilişsel okuduğunu anlama farkındalı̆̆ını kazanması için yedinci sınıf öğrencilerinin daha uygun olduğu düşünülmüştür. Bu bağlamda araştırmanın evrenini il genelinde ilçeleri de kapsayan ortaokullarda öğrenim gören tüm 7. sınıf öğrencileri oluşturmaktadır. Örneklemini ise, il merkezindeki tüm ortaokullarda 7. Sınıf öğrencileri oluşturmaktadır. Bu bağlamda il merkezinde bulunan altı farklı ortaokula gidilerek önce okul müdürleri araştırmanın amacı hakkında konuşulmuştur. Okul müdürlerinin ve matematik öğretmenlerinin uygun gördüğ̈̈ ders saatlerinde 7. Sınıf öğrencilerine ulaşılmıştır. 7. Sınıfta öğrenim gören toplamda 301 öğrencinin cinsiyete göre dağılımı Tablo 1'de verilmiştir. 
Tablo 1.

Örneklemin Bazı Demografik Verilere Göre Dă̆ılımı

\begin{tabular}{lccc}
\hline Değişken & Alt Değişken & Frekans (n) & Yüzde \\
\hline \multirow{2}{*}{ Cinsiyet } & $\mathrm{K}$ & 147 & 48,8 \\
& $\mathrm{E}$ & 154 & 51,2 \\
\hline TOPLAM & & 301 & 100 \\
\hline
\end{tabular}

Tablo 1 incelendiğinde örneklemin cinsiyet ( $\mathrm{K}_{1 \mathrm{Z}}=\%$ 48,8 $\mathrm{n}=147$; Erkek=\% 51,2 $\left.\mathrm{n}=154\right)$ üzerinde hemen hemen dengeli bir dağılım gösterdiği söylenebilir.

\subsection{Veri Toplama Araçları}

Bu çalışma kapsamında iki tane veri toplama aracı kullanılmıştır. Bu araçlardan ilki Duran (2011) tarafından geliştirilen Görsel Matematik Okuryazarlı̆ğ Öz-yeterlik Alg1 Ölçeği, diğeri Gelen (2003) tarafından geliştirilip Çakıroğlu (2007) tarafından uyarlanan Üstbilişsel Okuduğunu Anlama Farkındalık Ölçeğidir.

\section{Görsel Matematik Okuryazarlığı Öz-yeterlik Algı Ölçeği (GMOÖAÖ)}

Duran (2011) tarafindan öğrencilerinin GMOÖA puanlarını belirlemek için Görsel Matematik Okuryazarlığı Özyeterlik Algı Ölçeği geliştirilmiştir. GMOÖAÖ olarak tanımlanan ölçek 38 maddeden oluşup 5'li likert tipinde hazırlanmıştır. Ölçekteki her bir madde "hiçbir zaman", "nadiren”, "bazen", "sık sık" ve "her zaman" şeklinde derecelendirilmiştir. Bu ölçek yedinci sınıfta öğrenim gören öğrencilere uygulanmıştır. Ölçeğin güvenirliği için hem ölçeğin hem de her bir faktörün iç tutarlık ölçütü olan Cronbach Alpha $(\alpha)$ katsayısı .94 olarak hesaplanmıştır. Böylece ölçeğin güvenilir olduğu kabul edilmiştir. Ölçekteki 38 madde açımlayıcı faktör analizi sonucunda toplam varyansın \% 41,81' ni açıkladığ 1 ifade edilmiştir. GMOÖAÖ'deki olumlu maddeler, "hiçbir zaman" seçeneğinden "her zaman" seçeneğine olmak üzere 1'den 5'e doğru; olumsuz maddeler ise "hiçbir zaman" seçeneğinden "her zaman” seçeneğine olmak üzere 5'den 1'e doğru puanlanmıştır. GMOÖAÖ’den alınabilecek en düşük puan 38, en yüksek puan ise 190'dır. Alınabilecek 38 puan en düşük, 190 puan da en yüksek düzeyde GMOÖA seviyesini göstermektedir. Puanın yüksekliği öğrencilerin algılarının yüksekliğini, puanın düşüklüğü de bu algının düşüklüğünü gösterir.

\section{Üstbilişsel Okuduğunu Anlama Farkındalık Ölçeği (ÜOAFÖ)}

Gelen (2003) tarafından geliştirilip Çakıroğlu (2007) tarafından Üstbilişsel Okuduğunu Anlama Farkındalık Ölçeği uyarlanmıştır. Ölçek 30 maddeden oluşmaktadır. Her bir madde için üç şık belirlenmiştir. Ölçek her madde için en az istenenden (1), en çok istenene doğru (3) bir derecelendirmeyi içermekte, öğrenci o soru ile ilgili olarak bu üç seçenekten en uygun olanı seçmektedir. Buna göre ölçekten alınabilecek en düşük puan 30, en yüksek puan ise 90 olmaktadır. Bu ölçek yedinci sınıfta öğrenim gören öğrencilere uygulanmıştır. Ölçeğin Croanbach Alpha güvenirlik katsayısı 0,74 olarak bulunmuştur. Bu sayısal değer, güvenirlik için gerekli en az değer olan korelasyon katsayısı .70'in üzerindedir. Bu nedenle ölçeğin güvenilir olduğu kabul edilebilir (Büyüköztürk, 2004). Ölçek için yapılan faktör analizinde Gelen (2003), ölçeğin alt boyutlarıyla birlikte bir anlam ifade ettiğini ve bir bütünlük oluşturduğunu tespit etmiştir. Bu sebeple ölçek alt boyutlara indirgenmeden bir bütün olarak ele alınıp uygulanmıştır.

\subsection{Verilerin Analizi}

Araştırma verilerinin analizinde, öncelikle verilerin normal dağılıp dağılmadığı kontrol edilerek, verilerin normal dağıldığı belirlenmiştir. Daha sonra ilgilenilen değişkenler açısından cinsiyete göre bir farklılık olup olmadığını tespit edebilmek için analiz yöntemi olarak bağımsız örneklem t testi kullanılmıştır. Verilerin analizinde basit korelasyon analizi kullanılmıştır. Ayrıca çalışmanın güvenirliği için görsel matematik okuryazarlık öz-yeterlik algıları ve üstbilişsel okuduğunu anlama farkındalığı ölçeğinin Cronbach Alfa güvenirlik katsayıları sırasıyla .94 ve .77 bulunmuştur.

\section{BULGULAR}

Çalışmada ortaokul öğrencilerinin görsel matematik okuryazarlık algıları ile üstbilişsel okuduğunu anlama farkındalığı arasındaki ilişkileri araştırmak amaçlanmıştır. Bu bağlamda belirlenen problem ve alt problemler doğrultusunda, öğrencilerin ölçeklere verdikleri yanıtlar sayısallaştırılarak sırasıyla tablolar halinde bulgular sunulmuştur. İlk olarak aşağıda verilen Tablo 2'de GMOÖAÖ ve ÜOAFÖ puanlarına ilişkin betimsel istatistikler yer almaktadir. 
Tablo 2.

GMOÖAÖ ve ÜOAFÖ Puanlarına İlișkin Betimsel İstatistikler

\begin{tabular}{lcccc}
\hline Değişken & $\overline{\mathrm{X}}$ & ss & Çarpıklık & Basıklık \\
\hline ÜOAF & 69,65 & 7,68 & $-0,39$ & $-0,18$ \\
GMOÖA & 144,93 & 23,95 & $-0,42$ & $-0,62$ \\
\hline
\end{tabular}

Tablo 2'de ölçek puanlarının dağılımları çarpıklık ve basıklık değerleri açısından göz önüne alındığında tümünün -1,96 ile 1,96 arasında olmasından dolayı çok değişkenli normal dağılıma uygunluk gösterdiği söylenebilir (Kline, 2011).

Araştırmanın katılımcılarını oluşturan ortaokul 7. sınıf öğrencilerinin cinsiyet açısından görsel matematik okuryazarlığı öz-yeterlik algıları ile üstbilişsel okuduğunu anlama farkındalığı arasında anlamlı farklılık olup olmadığını incelemek için İki ortalama arasındaki farkın anlamlılık testi olan bağımsız örneklem t testi tekniği kullanılmıştır. Bu duruma ilişkin bulgular Tablo 3'te ayrıntılı bir şekilde sunulmuştur.

Tablo 3.

GMÖ̈AÖ ve ÜOAFÖ Puanlarının Cinsiyete Göre Farklılıkları

\begin{tabular}{|c|c|c|c|c|c|c|c|}
\hline Değişken & Cinsiyet & $\mathbf{N}$ & $\overline{\mathrm{X}}$ & ss & $t$ & $s d$ & $p$ \\
\hline \multirow{2}{*}{ ÜOAF } & $\mathrm{K} 1 \mathrm{Z}$ & 147 & 71,21 & 6,99 & \multirow{2}{*}{3,49} & \multirow{2}{*}{299} & \multirow{2}{*}{0,001} \\
\hline & Erkek & 154 & 68,17 & 8,03 & & & \\
\hline \multirow{2}{*}{ GMOÖA } & $\mathrm{K}_{1 \mathrm{Z}}$ & 147 & 147,51 & 24,00 & \multirow{2}{*}{1,83} & \multirow{2}{*}{299} & \multirow{2}{*}{0,07} \\
\hline & Erkek & 154 & 142,47 & 23,71 & & & \\
\hline
\end{tabular}

Tablo 3'te görüldüğü üzere, cinsiyet açısından üst bilişsel okuduğunu anlama farkındalığı puanlarının istatistiksel olarak anlamlı bir farklılık gösterdiği anlaşılmaktadır $\left(\mathrm{t}_{0.05: 299}=3,49, p<0,01\right)$. Kız öğrencilerin üst bilişsel okuduğunu anlama farkındalığı puan ortalamaları $(\bar{X}=71,21$, ss $=6,99)$ erkek öğrencilerin üst bilişsel okuduğunu anlama farkındalığı puan ortalamalarından $(\bar{X}=68,17$, ss $=8,03)$ istatistiksel olarak anlamlı biçimde daha yüksektir. Bu sonuçlar değerlendirildiğinde kızların üst bilişsel okuduğunu anlama düzeylerinin erkeklerin üst bilişsel okuduğunu anlama düzeylerinden daha yüksek olduğu tespit edilmiştir.

Diğer taraftan cinsiyet açısından görsel matematik okuryazarlığı öz-yeterlik algı puan ortalamalarının, istatistiksel olarak anlamlı bir farklılık göstermediği anlaşılmaktadır $\left(\mathrm{t}_{0.05: 299}=1,83, p>0,05\right)$. Dolayısıyla, kızların ve erkeklerin görsel matematik okuryazarlığı öz-yeterlik algı düzeylerinin birbirlerini yakın oldukları ifade edilebilir.

Ortaokul 7. sınıf öğrencilerinin üst bilişsel okuduğunu anlama farkındalığı ile görsel matematik okuryazarlığı öz yeterlik algıları arasında ilişkiyi belirleyebilmek için korelasyon analizi gerçekleştirilmiştir. Analiz sonucunda (Tablo 4), öğrencilerin ÜOAF ile GMOÖA arasında pozitif yönde anlamlı ilişki olduğu anlaşılmıştır [r $\mathrm{r}_{(301)}=0,51$, $p<0,001]$.

\section{Tablo 4.}

GMÖ̈AÖ ve ÜOAFÖ Arasındaki İlişki

\begin{tabular}{|c|c|c|c|}
\hline \multirow{2}{*}{ Değişken } & \multicolumn{2}{|c|}{ GMOÖA } & \multirow{2}{*}{$\mathbf{N}$} \\
\hline & $r$ & $p$ & \\
\hline ÜOAF & 0,51 & 0,001 & 301 \\
\hline
\end{tabular}

Ortaokul 7. sınıf öğrencilerinin görsel matematik okuryazarlığı öz-yeterlik algılarının onların üst bilișsel okuduğunu anlama farkındalığı düzeylerini yordayıp yordamadığını belirlemek amacıyla regresyon analizi gerçekleştirilmiştir. Regresyon analizine cinsiyet kontrol değişkeni olarak dâhil edilmiştir. Bulgular Tablo 5 'te yer almaktadir. 
Tablo 5.

GMOÖA'nın ÜOAF'nı Yordamasına Yönelik Regresyon Analizi Sonuçları

\begin{tabular}{lccccccc}
\hline Değişkenler & $\boldsymbol{B}$ & $\boldsymbol{S H}_{\boldsymbol{B}}$ & $\boldsymbol{\beta}$ & $\boldsymbol{t}$ & $\boldsymbol{R}^{2}$ & $\boldsymbol{A R}^{\mathbf{2}}$ & $\boldsymbol{F}$ \\
\hline Cinsiyet & $-2,25$ & 0,76 & $-0,15$ & $-2,96^{* *}$ & \multirow{2}{*}{0,28} & \multirow{2}{*}{0,28} & \multirow{2}{*}{$58,84^{* *}$} \\
GMOÖA & 0,16 & 0,02 & 0,50 & $10,07^{* *}$ & & & \\
\hline
\end{tabular}

Not. ${ }^{* *} p<.01$

Tablo 5'te görülen regresyon sonuçlarına göre cinsiyet istatistiksel olarak kontrol edildiğinde; görsel matematik okuryazarlığı öz-yeterlik algısının üst bilişsel okuduğunu anlama farkındalığını yordadığı ve bu modelin anlamlı olduğu anlaşılmaktadır, $\left(F_{(2,298)}=58,84, p<0,01\right)$. Görsel matematik okuryazarlığı öz-yeterlik algısı, üst bilişsel okuduğunu anlama farkındalığı toplam varyansının \%28'ini açıklamaktadır, $\left(R^{2}=0,28\right.$, düzenlenmiş $\left.R^{2}=0,28\right)$. Regresyon modeli incelendiğinde, görsel matematik okuryazarlığı öz-yeterlik algısı, ortaokul öğrencilerinin üst bilişsel okuduğunu anlama farkındalı̆̆ düzeylerini pozitif yönde anlamlı yordamaktadır $(\beta=0,50, p<0,01)$.

\section{TARTIŞMA, SONUÇ ve ÖNERILLER}

1739 sayılı Millî Eğitim Temel Kanunu’nda belirlenmiş olan Genel Amaçlar ve Temel İlkeler doğrultusunda 2017 yılında hazırlanan Matematik Dersi Öğretim Programı'nın ulaşmaya çalıştığı genel amaçlardan bazıları şunlardır (MEB, 2017).

Öğrenci;

1- Matematiksel okuryazarlık becerilerini geliştirebilecek ve etkin bir şekilde kullanabilecektir.

2- Matematiksel kavramları anlayabilecek, bu kavramları günlük hayatta kullanabilecektir.

3- Üstbilişsel bilgi ve becerilerini geliştirebilecek, kendi öğrenme süreçlerini bilinçli biçimde yönetebilecektir.

Yukarıdaki maddelerden görüldüğü üzere öğrencilerin matematik okuryazarlığı ve üstbilişsel bilgi ve becerilerinin geliştirilmesine önem verilmektedir. Nitekim bu araştırmanın sonuçlarında da görsel matematik okuryazarlığının üst bilişsel okuduğunu anlama farkındalığını yordadığı belirlenmiştir. Diğer yandan okuduğunu anlama becerilerinin de matematik başarısını olumlu etkilediğine ilişkin birçok çalışma bulunmaktadır (Adelson, Dickinson \& Cunningham, 2015; Erdem, 2016; Hooper, Roberts, Sideris, Burchinal \& Zeisel, 2010; Sertöz, 2003; Tatar \& Soylu, 2006). Bu bağlamda matematik dersinde hedeflenen başarıya ulaşmalarında okuduğunu anlama becerilerinin arasında yakın bir ilişki olduğu söylenebilir.

$\mathrm{Bu}$ araştırmanın diğer sonuçları arasında ortaokul öğrencilerinin ÜOAF düzeylerinin cinsiyete göre anlamlı farklılık gösterdiği sonucuna ulaşılmıştır. Kız öğrencilerin puanlarının erkek öğrencilerin puanlarından daha yüksek olduğu görülmektedir. Güngör (2005) çalışmasında 6, 7 ve 8. sınıf öğrencilerin okuduğunu anlama stratejilerini kullanıma düzeylerinin, cinsiyetlerine göre kızlar lehine farklılık gösterdiğini bulmuştur. Nitekim bu çalışmada kızların ÜOAF düzeylerinin yüksek olması, kız öğrencilerin okuduğunu anlama stratejilerini kullanmada daha başarılı olmalarına dayandırılabilir. Buna ilavaten ortaokul öğrencilerinin GMOÖA düzeylerinin cinsiyete göre anlamlı farklılık göstermediği sonucuna ulaşılmıştır. Öğrencilerinin görsel matematik okuryazarlığına yönelik öz-yeterlik algılarının kızlar lehine (Özdemir, Duran \& Kaplan, 2016; Özgen \& Bindak, 2011) veya erkekler lehine (Sarı Uzun, Yanık, \& Sezen, 2012) farklılaştığı ya da cinsiyete göre değişmediğini (Birgün \& Gülbez, 2014; Duran, 2011) gösteren çalışmalar literatürde yer almaktadır. Bu sonuçlardan yola çıkarak öğrencilerin GMOÖA düzeylerinin cinsiyete göre anlamlı farklılık göstermemesi hakkında net bir yorum yapılamamaktadır.

Bu çalışma kapsamında GMOÖA ile ÜOAF arasında pozitif yönde orta düzeyde bir ilişki bulunmuştur. Çalışmada ayrıca öğrencilerin görsel matematik okuryazarlığ̣ öz-yeterlik algılarının, üstbilişsel okuduğunu anlama farkındalık düzeylerini pozitif yönde anlamlı bir şekilde yordadığı sonucuna ulaşılmıştır. Bu durum benzer çalışmalar tarafından desteklenmektedir. Örneğin; Kıvrak (2014) yaptığı çalışmada 6 ve 7. sınıf öğrencilerin okuma-anlama becerileri ile matematik başarıları arasında pozitif yönde bir ilişsi bulmuştur. Yani altıncı ve yedinci sınıf öğrencilerinde, Türkçe testinde başarı oranı yüksek olan öğrencilerin Matematik testinde de başarılı oldukları görülmüştür. Yine Adelson vd. (2015) tarafından matematik ve okuma başarısı arasında ortaya çıkarılan pozitif yönde yüksek düzeydeki ilişkiyle desteklenmektedir. Benzer şekilde Gürsakal (2012) PISA araştırması olan Türkiye örneklemi kullanılarak yapılan bir çalışmasında öğrencilerin okuma becerileri ve matematik okuryazarlığı arasında pozitif yönlü ve oldukça kuvvetli bir ilişki tespit etmiştir.

Caponera, Sestito, Russo (2016) yaptıkları çalışmalarında 2011 yılında yapılan TIMMS(Trends in International Mathematics and Science Study) ve PIRLS(Progress in International Reading Literacy Study) sınavlarındaki verileri analiz etmişlerdir. Araştırmacılar katılımcıların okuma okuryazarlığı ile matematik okuryazarlığı arasında pozitif bir ilişki tespit etmişlerdir. 
Görüldüğü üzere okuma yeteneği veya okuma okuryazarlığı ile matematik başarısı veya matematik okuryazarlığ1 arasında genellikle pozitif bir ilişki bulunmuştur. Bu çalışmada da buna paralel olarak öğrencilerin üstbilişsel okuduğunu anlama farkındalıkları ile görsel matematik okuryazarlık algıları arasında pozitif bir ilişkinin olması gayet doğaldır. Nitekim uluslararası sınavlar olan PISA ve TIMMS gibi sınavlarda da öğrencilerin okuduğunu anlamaya ve görsel ifadeleri yorumlamaya ilişkin matematik sorularının olduğu bilinmektedir. Ayrıca bu sorularda verilen görsel ifadelere ilişkin öğrencilerin okuryazar olması beklenmektedir. Son yıllarda ülkemizde yapılan ulusal sınavlarda da üstbilişsel okuduğunu anlamaya ilişkin matematik sorularına daha ağırlık verilmektedir. Araştırmadan elde edilen sonuçlar doğrultusunda üstbilişsel okuduğunu anlama farkındalığı ile görsel matematik okuryazarlığı ile ilgili bazı öneriler aşağıda verilmiştir:

$\checkmark$ Gerek ulusal gerekse uluslararası sınavlarda üstbilişsel okuduğunu anlamaya yönelik soruların olacağı düşünüldüğünde, matematik öğrenme-öğretme süreçlerinde buna önem verilmelidir. Bu bağlamda soru çözümünde öğrencilerin problem/soruyu anlayıp öğrencilerin grafik, tablo, şekil, modelleme vb. görsel araçları kendisinin oluşturup yorumlanmasına fırsat verilmelidir. Problem/sorunun anlaşılması için üstbilişsel olarak okuduğunu anlama becerisinin kullanmasına önem verilmelidir. Bu bağlamda üstbilişsel okuduğunu anlamaya yönelik farkındalığı kazandıracak günlük yaşamdan gerçek problem durumlarına yer verilmelidir.

Araştırma ile ilgili olarak daha geniş araştırma örnekleminde konu ile ilgili farklı ölçekler kullanılarak veya deneysel çalışmalar yapılarak detaylı bilgi edinilebilir. Görsel matematik okuryazarlığ 1 ve üstbilişsel okuduğunu anlamaya yönelik farkındalığı etkileyen başka faktörler belirlenebilir.

$\checkmark$ Farkındalıkları veya algıları yüksek olan öğrencilerin, üstbilişsel okuduğunu anlama düzeylerinin ve görsel matematik okuryazarlık düzeylerinin belirlenmesine yönelik çalışmalar yapılabilir. Daha sonra aralarında nasıl bir ilişki olduğuna bakılabilir. 


\section{KAYNAKÇA}

Abu-Hilal, M.M. (2000). A structurel model for predicting mathematics achievement: Its relation with anxiety and self-concept in mathematics. Psychological Reports, 86, 835-847.

Adelson, J. L., Dickinson, E. R., \& Cunningham, B. C. (2015). Differences in the readingmathematics relationship: A multi-grade, multi-year statewide examination. Learning and Individual Differences, 43, 118-123.

Altındağ, M. (2008). Hacettepe üniversitesi eğitim fakültesi öğrencilerinin yürütücü biliş̧ becerileri. (Yayınlanmamış Yüksek Lisans Tezi), Hacettepe Üniversitesi, Ankara.

Ayotola, A., \& Adedeji, T. (2009). The relationship between mathematics self-efficacy and achievement in mathematics. Procedia-Social and Behavioral Sciences, 1 (1), 953-957.

Bağçeci, B., Döş, B., \& Sarıca, R. (2011). İlköğretim öğrencilerinin üstbilişsel farkındalık düzeyleri ile akademik başarısı arasındaki ilişkinin incelenmesi/An analysis of metacognitive awareness levels and academic achievement of primary school students. Mustafa Kemal Üniversitesi Sosyal Bilimler Enstitüsü Dergisi, 8(16), 551-566.

Baydık, B. (2011). Okuma güçlüğü olan öğrencilerin üstbilişsel okuma stratejilerini kullanımı ve öğretmenlerinin okuduğunu anlama öğretim uygulamalarının incelenmesi. Ĕgitim ve Bilim, 36(162). 301-319.

Bekdemir, M. \& Duran, M. (2012). İlköğretim öğrencileri için görsel matematik okuryazarlı̆̆ öz-yeterlik alg1 ölçeği (GMOYÖYAÖ)" nin geliştirilmesi. Ondokuz Mayls Üniversitesi Eğitim Fakültesi Dergisi, 31(1), 89-115.

Birgin, O., \& Gülbez, B. (2014). Ortaokul 6-8.sinıf öğrencilerinin görsel matematik okuryazarllk öz-yeterlik algllarının incelenmesi. 11. Ulusal Fen Bilimleri ve Matematik Eğitimi Kongresi’nde sunulmuş bildiri, Çukurova Üniversitesi, Adana, Türkiye.

Blake, S., \& Lesser, L. (2006). Exploring the relationship between academic self-efficacy and middle school students' performance on a high-stakes mathematics test. Teacher Education-Inservice/Professional Development, 2, 655-656.

Bonds, C. W., Bonds L. G. \& Peach W. (1992). “Metacognition: Developing independence in learning”, Clearing House, 66, 56-59.

Bozkurt, M., \& Memiş, A. (2013). Beşinci sınıf öğrencilerinin üstbilişsel okuduğunu anlama farkındalığı ve okuma motivasyonları ile okuma düzeyleri arasındaki ilişki. Ahi Evran Üniversitesi Kırşehir Eğitim Fakültesi Dergisi, 14(3). 147-160.

Büyüköztürk, Ş. (2004). Veri analizi el kitabı. Ankara: Pegem A Yayıncılık

Caponera, E., Sestito, P., \& Russo, P. M. (2016). The influence of reading literacy on mathematics and science achievement. The Journal of Educational Research, 109(2), 197-204.

Chen, P.P. (2003). Exploring the accurary and predictability of the self-efficacy beliefs of seventh grade mathematics students. Learning and Individual Differences, 14, 79-92.

Çakıroğlu, A. (2007). Üstbilişsel strateji kullanımının okuduğunu anlama düzeyi düşük öğrencilerde erişi artırımına etkisi, (Yayımlanmamış doktora tezi) Gazi Üniversitesi, Ankara.

Çilingir, E. (2015). Gerçekçi matematik eğitimi yaklaşımının ilkokul öğrencilerinin görsel matematik okuryazarlı̆̆ düzeyine ve problem çözme becerilerine etkisi, (Yayımlanmamış yüksek lisans tezi), Çukurova Üniversitesi, Adana.

Çilingir, E. \& Artut, P.D. (2016). Gerçekçi matematik eğitimi yaklaşımının ilkokul öğrencilerinin başarılarına, görsel matematik okuryazarlığı öz-yeterlik algılarına ve problem çözme tutumlarına etkisi. Turkish Journal of Computer and Mathematics Education. 7 (3). 578-600.

Duran, M. (2011). İlköğretim 7.sınıf öğrencilerinin görsel matematik okuryazarlı̆̆ı öz-yeterlik algıları ile görsel matematik başarıları arasındaki ilişsi. (Yayınlanmamış yüksek lisans tezi) Erzincan Üniversitesi, Erzincan.

Erdem, E. (2016). Matematiksel muhakeme ile okuduğunu anlama arasındaki ilişki: 8. sınıf örneği. Necatibey Eğitim Fakültesi Elektronik Fen ve Matematik Eğitimi Dergisi, 10(1). 393-414.

Gelen, İ. (2003). Bilişsel farkındallk stratejilerinin Türkçe dersine ilişkin tutum, okuduğunu anlama ve kalıcllğa etkisi. (Yayımlanmamış doktora tezi) Çukurova Üniversitesi, Adana.

Güngör, A. (2005). Altıncı yedinci ve sekizinci sınıf öğrencilerinin okuduğunu anlama stratejilerini kullanma düzeyleri. Hacettepe Üniversitesi Eğitim Fakültesi Dergisi, 28(28). 101-108.

Gürsakal, S. (2012). PISA 2009 öğrenci başarı düzeylerini etkileyen faktörlerin değerlendirilmesi. Süleyman Demirel Üniversitesi Iktisadi ve İdari Bilimler Fakültesi Dergisi, 17(1). 441-452.

Göçer, A. \& Tabak, G. (2013). Öğretmen adaylarının görsel okuryazarlıkla ilgili algılları. Adıyaman Üniversitesi Sosyal Bilimler Enstitüsü Dergisi, 6(11), 518-541. 
Hooper, S. R., Roberts, J., Sideris, J., Burchinal, M., \& Zeisel, S. (2010). Longitudinal predictors of reading and math trajectories throughmiddle school for African American versus Caucasian students across two samples. Developmental Psychology, 46, 1018-1029.

Kıvrak, Y. (2014). Okuma-anlamadaki başarının matematik başarısına etkisi. (Yayınlanmamış yüksek lisans tezi), Uludağ Üniversitesi, Bursa.

Kline, R. B. (2011). Principles and practice of structural equation modeling (3rd ed.). New York, NY: Guilford Press.

Kuruyer, H. G., \& Özsoy, G. (2016). İyi ve zayıf okuyucuların üstbilişsel okuma becerilerinin incelenmesi: Bir durum çalışması. Kastamonu Ĕ̈itim Dergisi, 24(2), 771-788.

Liu, X., \& Koirala, H. (2009). The effect of mathematics self-efficacy on mathematics achievement of high school students. Paper presented at the annual conference of the Northeastern Educational Research Association, University of Connecticut, Connecticut.

MEB (2011). PISA Türkiye. EĞİTEK Yayıları, Ankara. http://pisa.meb.gov.tr/wpcontent/uploads/2013/07/PISA-kitab\%C4\%B1.pdf .

MEB, (2015). PISA 2015 Ulusal Nihai Raporu. Millî Eğitim Bakanlığı, Ölçme, Değerlendirme ve Sınav Hizmetleri Genel Müdürlüğü, Ankara.

MEB, (2017). Matematik dersi öğretim programı (ilkokul ve ortaokul 1,2,3,4,5,6,7 ve 8. sınıflar), Ankara. http://mufredat.meb.gov.tr/ProgramDetay.aspx?PID=191.

Özdemir, F., Duran, M, \& Kaplan, A. (2016). Ortaokul öğrencilerinin görsel matematik okuryazarlığı öz-yeterlik algıları ile problem çözme beceri algılarının incelenmesi. Kuramsal Ĕgitimbilim Dergisi, 9(4), 532-554.

Özgen, K., \& Bindak, R. (2011). Lise öğrencilerinin matematik okuryazarlığına yönelik öz-yeterlik inançlarının belirlenmesi. Kuram ve Uygulamada Ĕgitim Bilimleri, 11 (2), 1073-1089.

Özsoy, G., Çakıroğlu A., Kuruyer H.G. ve Özsoy S. (2010). Sınıf Öğretmeni Adaylarının Üstbilişsel Farkındalık Düzeylerinin Bazı Değişkenler Bakımından İncelenmesi, 9. Sınıf Öğretmenliği Eğitimi Sempozyumu,, Elazı̆̆, 489-492.

Sarı Uzun, M., Yanık, C., \& Sezen, N. (2011). Öğretmen adaylarının matematik okuryazarlığı öz-yeterliklerinin incelenmesi. Hacettepe Üniversitesi Eğitim Fakültesi Dergisi, 2, 212-221.

Sertöz, T. (2003). İlköğretim okullarının 6. sınıflarında okuduğunu anlama davranışının kazandırılmasının matematik başarısına etkisi. Yayımlanmamış Yüksek lisans Tezi. Marmara Üniversitesi. Eğitim Bilimleri Enstitüsü, İlköğretim Anabilim Dalı. İstanbul.

Şahin, Ç., Kurudayığlu, M. \& Çelik. G.(2013). Türkçe öğretmeni adaylarının görsel okuryazarlıkları üzerine bir araştırma. Ana Dili Ĕgitim Dergisi, 1(1), 129-143.

Şengül, S., Katrancı, Y. \& Gülbağcı, H. (2012). İlköğretim ikinci kademe öğrencilerinin görsel matematik okuryazarlığı öz-yeterlik algılarının incelenmesi. 21. Ulusal Eğitim Bilimleri Kongresinde sunulan bildiri, Marmara Üniversitesi, Istanbul.

Tanoğlu, Ş., Taşkesen, O., Bakırhan, A. \& Taşkesen, S. (2017). 5. 6. ve 7.sınıf öğrencilerinin üç boyutlu nesneleri çizim başarısı ile görsel matematik okuryazarlığı öz-yeterlik algıları arasındaki ilişkinin incelenmesi. Journal of Strategic Research in Social Science. 3(2). 29-40.

Tatar, E. \& Soylu, Y. (2006). Okuma-anlamadaki başarının matematik başarısına etkisinin belirlenmesi üzerine bir çalışma. Kastamonu Ĕ̈itim Dergisi. 14(2). 503-508.

Tutkun, F. O., Erdoğan, D. G., \& Öztürk, B.(2014). Levels of visual mathematics literacy self-efficacy perception of the secondary school students. Middle Eastern \& African Journal of Educational Research, 8, 1927. 


\section{EXTENDED ABSTRACT}

\section{Introduction}

PISA was defined in 2012 as a type of mathematical literacy involving the individual's capacity to formulate, use and interpret mathematics. This capacity of mathematical reasoning involves using mathematical concepts, processes and tools to explain and estimate a case. Mathematical literacy aids the individual in becoming aware of and comprehending the role of mathematics in the world, reaching judgments based on solid foundations, and being a constructive, concerned and sensitive citizen who can fulfill their own needs (MEB, 2011). Additionally, there is literacy types defined for different lessons, apart from the mathematic literacy in PISA. Apart from these, another literacy type that has been encountered in learning-teaching processes in recent years that appears important is visual literacy. A student with visual literacy skills is considered to better understand the underlying messages of visual aids presented during lessons (Şahin, Kurudayığlu, Çelik, 2013). As a result, there is a need for a literacy type based fully on visual stimuli to understand and explain visual aids (Göçer and Tabak, 2013). In mathematics the new concept of visual mathematic literacy has been defined as the skill of reading, interpreting, assessing, and using figures, tables, graphs, pictures, non-visual figures etc. and creating new visual states (Çilingir and Artut, 2016). Bekdemir and Duran (2012) defined the problems of visual mathematic literacy as sufficiency in mathematically perceiving, stating, interpreting, assessing, applying and using visual or spatial or contrarily visual or spatial information that may be encountered in daily life.

When the relevant literature is investigated (Abu-Hilal, 2000; Chen, 2003; Blake and Lesser, 2006; Ayotola and Adedeji, 2009; Liu and Koirala, 2009; Özgen and Bindak, 2011; Şengül, Katranc1 and Gülbağc1, 2012), there is a significant relationship between the mathematical literacy self-efficacy of students and their mathematical achievements. Mathematics educators have stated the necessity to use studies and activities related to visual mathematics to develop the power of visual/pictorial thinking. Additionally, studies (Tanoğlu, Taşkesen, Bakırhan and Taşkesen, 2017) have more often investigated the relationship between geometry and visual mathematic literacy self-efficacy perception points. It is thought that how a topic other than geometry will affect the visual mathematic literacy self-efficacy perception points will be valuable research. In this way, this study is considered to contribute to the field by investigating the relationship between the visual mathematic literacy perception of middle school students and awareness of metacognitive reading comprehension. As a result, the aim of the study was determined as to research the correlation between the visual mathematic literacy perceptions and awareness of metacognitive reading comprehension of middle school students. In other words, whether the visual mathematic literacy self-efficacy perceptions of students is a significant predictor of awareness levels of metacognitive reading comprehension was researched. Additionally, a sub-aim of the study was to research whether awareness of metacognitive reading comprehension and visual mathematic literacy self-efficacy perception points differed according to sex.

\section{Method}

To research the correlation and prediction of visual mathematic literacy perceptions and awareness of metacognitive reading comprehension of 7th grade middle school students, the quantitative research paradigm was appropriate and a correlative research model was used in the study. The population of the research comprised students attending 7th grade of middle school. The study included 301 volunteer students. Within this research, two data collection tools were used. The first was the Visual Mathematic Literacy Self-Efficacy Perception Scale (VMLSEP) developed by Duran (2011). This scale includes 38 items with a 5-point Likert answer scale. The other scale used in this study was the 30-item Awareness of Metacognitive Reading Comprehension scale (AMRC) developed by Gelen (2003) and adapted to Turkish by Çakıroğlu (2007).

Before collecting data, official permission was granted from the Ministry of National Education to apply the scales in middle schools. The students were given 1 lesson hour as duration. Data were checked for normal distribution. When the skewness and kurtosis values of the distribution of scale points are considered, they may be said to fit normal multivariate distribution as all were between -1.96 and 1.96 (Kline, 2011). Additionally for reliability of the study, the Cronbach alpha reliability coefficient for the VMLSEP and the AMRC were found to be 0,94 and 0,77 .

\section{Findings, Discussion and Results}

To identify whether there was a difference in the variables based on sex, the independent samples t test was used as the analysis method. In terms of sex, the AMRC points were understood to show a significant difference ( $t_{0.05}$ $299=3,49, p<0,01$ ). The mean AMRC points for female students ( $\bar{X}=71,21$, ss $=6,99$ ) were significantly higher than the mean AMRC points for male students $(\bar{X}=68,17$, ss $=8,03$ ). However, the mean VMLSEP points did not display a statistically significant difference in terms of sex $\left(\mathrm{t}_{0.05: 299}=1,83, p>0,05\right)$. 
Correlation analysis was completed to determine the correlation between AMRC and VMLSEP of 7th class middle school students. The results of the analysis found a positive significant correlation between AMRC and VMLSEP $\left[\mathrm{r}_{(301)}=0,51, p<0,001\right]$.

Regression analysis was completed to determine whether the VMLSEP of 7th class middle school students predicted the levels of AMRC. According to this analysis, it was understood that the model of VMLSEP predicting AMRC was significant $\left(F_{(2,298)}=58,84, p<0,01\right)$. VMLSEP explained $28 \%$ of the total variance of AMRC $\left(R^{2}=\right.$ 0,28 , uncorrected $\left.R^{2}=0,28\right)$. When the regression model is investigated, VMLSEP significantly predicted AMRC levels in a positive direction among middle school students $(\beta=0,50, p<0,01)$.

When the results of the study are examined, it was concluded that the AMRC levels of 7th class middle school students differed significantly according to sex. The points for female students appear to be higher than the points for male students. Similarly, the study by Güngör (2005) found that the level of use of reading comprehension strategies among 6th, 7th and 8th class students differed according to sex in favor of females. However, the conclusion was reached that VMLSEP levels of middle school children did not differ significantly according to sex. A study by Şengül, Katrancı and Gülbağc1 (2012) on the VMLSEP of primary school second stage students aimed to investigate how this changed with class level, sex and mathematic achievement.

Another result of the study is the moderate positive correlation between VMLSEP and AMRC. The study also concluded that the visual mathematic literacy self-efficacy perception of students positively and significantly predicted levels of awareness of metacognitive reading comprehension. This situation is supported by similar studies. For example, the study by Kivrak (2014) found a positive correlation between the reading-comprehension skills and mathematic achievements of 6th and 7th class students. Again Adelson et al. (2015) supported a positive high level correlation between mathematic and reading achievements. Similarly, Gürsakal (2012), in a study using the Turkish sample of the PISA research, identified a positive and very strong correlation between the reading skills and mathematic literacy of students.

A study by Caponera, Sestito and Russo (2016) analyzed data from the TIMMS (Trends in International Mathematics and Science Study) and PIRLS (Progress in International Reading Literacy Study) exams held in 2011. The researchers identified a positive correlation between reading literacy and mathematic literacy. As can be seen, there is generally a positive correlation found between reading skills or reading literacy and mathematic achievement or mathematic literacy. In parallel, the positive correlation between AMRC and VMLSEP among students in this study is a natural conclusion. 